\title{
Intercultural Communicative Competence Cultivation in English and American Literature Teaching
}

\author{
Yan Liu \\ Teaching and Research Institute of Foreign Languages, Bohai University, Jinzhou, 121013, China \\ 2439989361@qq.com
}

Keywords: English and American literature; intercultural communicative competence; training strategy; course group; language using competence

\begin{abstract}
English and American literature contains a wealth of cultural and ethnic knowledge, to enhance students' cultural awareness, improve intercultural communicative competence and so has an important role. In this paper, based on the study of the English and American literature course group construction and intercultural communicative and comprehensive language using competence, the training strategy of intercultural communicative competence in the teaching of English and American literature is presented. Specific strategies include the use of translation teaching mode, through the modern educational technology to improve students' interest, to change the teaching idea of intercultural communicative competence, to strengthen cultural empathy training, to take consistent teaching methods and course content, and so on. The research content of this paper is of great practical significance to the cultivation of students' intercultural communicative competence of English language and literature majors.
\end{abstract}

\section{Introduction}

With the growing trend of economic globalization, the increasingly close links between the countries, more and more frequent exchanges, and culture is the ties of exchange and cooperation between the countries. Thus, penetration and integration between cultures is a new trend. In order to comply with the development of the times, to avoid misunderstandings in cultural exchange process because of not understand, and timely to carry on the cultivation of intercultural communicative competence has a very important role. Foreign language learning is not a pure language learning, the ultimate goal is to grasp culture and customs of the nation through language learning, and ultimately achieve the purpose of strengthening and enhancing the learners' communicative ability in the international community. Teaching purpose of English and American literature course is to cultivate students' ability to read, appreciate, understand English and American literature original, and master the basic knowledge and methods of literary criticism. Through reading and analyzing English and American literature works, to promote students' language basic functions and humanistic quality improve, to enhance students' understanding of Western literature and culture. There is a close relationship between the English and American literature teaching and intercultural communicative competence, the communicative competence cultivation is the important part of the teaching of English and American literature, intercultural competence training is to improve teaching effectiveness in English and American literature, English and American literature is effective way of intercultural communicative competence cultivation. Literature contains a wealth of cultural knowledge, through the study of the cultural knowledge, and enhances students' cultural awareness, improve intercultural communicative competence. This paper proposed intercultural communicative competence cultivation strategy in English and American literature teaching, and students' intercultural communicative competence for English and American literature majors has important practical significance, but is also a reference to students' intercultural communicative competence cultivation for other majors.

\section{Construction on Course Group of English and American Literature}

Course group construction is in accordance with the operating rules of the teaching system, promote 
overall system optimization process, it is a kind of curriculum model which is strongly advocated by the higher education. the different course with relativity or certain purpose choreography together to form a "group", systematic study and teach, with the characteristics of strong comprehensive and high integrity, and can greatly improve the quality of teaching and student professional level. Course group construction mainly emphasized on the following two points [1]: first, relevance, because the course group is an organic whole consists of many basic teaching content through interconnected, mutual integration, the overall planning formed related courses, from the point of view of the contents of each course, there are inheritance relations between each other longitudinal and transverse are intrinsically linked, but self-contained system; the second is the comprehensive, through the analysis of knowledge point contained the course, delete duplicate course content, and then re-decomposed for the content, the formation of new theoretical and experimental teaching system, to achieve the overall is greater than sum of the parts. Thus, the course group is to improve the cognitive structure of teaching object, and the nature of the teaching program in several courses related to or similar to form a rational structure, clear hierarchy, closely interrelated integration of organic groups. In this paper, the course group composed of English and American literature is shown in Fig. 1. In the actual teaching program formulation process, according to the specific situation of the school, professional and teacher training, course group related courses can make appropriate trade-offs or mergers, to facilitate the development of students' professional interests and characteristics of personnel training, in favor of intercultural communicative competence improvement, realizes the resource optimization and integration, improve teaching effectiveness.

\begin{tabular}{|c|c|}
\multicolumn{2}{c}{ Course group of English and American literature } \\
\hline English and American short story & English classical literature \\
\hline English literary classics reading & English modern and contemporary literature \\
\hline American literary classics reading & English and American literary criticism \\
\hline English and American children's literature & English poetry selected reading \\
\hline American classical literature & English prose selected reading \\
\hline American modern and contemporary literature & English theatre selected reading \\
\hline
\end{tabular}

Fig. 1. Constitute on course group of English and American literature

\section{Comprehensive Language Using Competence in Intercultural Communicative}

Intercultural communicative competence depends on the comprehensive language using competence, and the task of English teaching is to cultivate students' comprehensive language using competence. English is a language, communication is the purpose of learning English, and situation is the basis of communication activities. To create a good situation, it is both the basis for learning English, but also a way to learn English. Innovative teaching scenarios, to guide students to experience, participate in language practice, in the situation students can be immersive, and actively participate in language practice, play autonomy, speak their minds, improve the language using and expression skills. Form a comprehensive language using competence based on students' language skills, language knowledge, emotional attitudes, learning strategies and cultural awareness on the overall development of literacy, shown in Fig. 2 [2]. Language knowledge and language skills are the basis of comprehensive language using competence, and cultural awareness is the guarantee of appropriate use of language. Emotional attitude is an important factor affecting student learning and development, learning strategies is the guarantee of improving the learning efficiency and developing self-learning ability. These five aspects together promote the formation of comprehensive language using competence. 


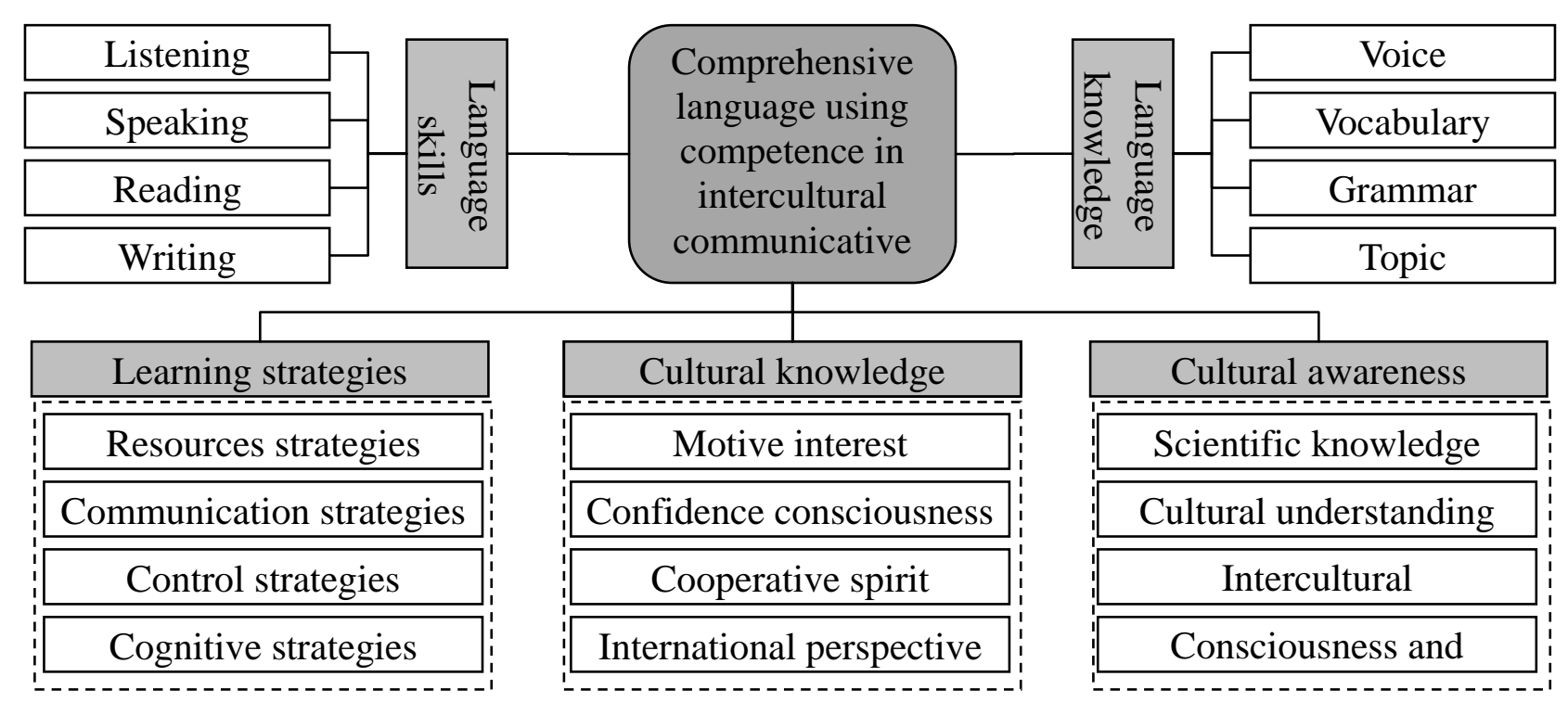

Fig. 2. Comprehensive language using competence in intercultural communicative

(1) Language skills. Listening, speaking, reading, writing and other basic language skills constitute an important part of language communicative competence, is the foundation of the comprehensive language using competence. Specifically the wording is accurate, semantic understand, properly structured, concise statement, Arts and penetration, plain language, normative. The accurate words, semantic structure, concise statement, understand correctly, and, through simple language, normative. In the process of language learning, it is both content and method. Teachers should pay attention to the following aspects: to carry out a large number of language training; to deal with the relationship between "listening, speaking, reading and writing", and making full use of the classroom environment to improve the quality of input and output.

(2) Language knowledge. It is an integral part of comprehensive language using competence, is an important foundation for the development of language skills, including pronunciation, vocabulary, grammar, functions, and other topics. Around the language knowledge, the teaching process should pay attention to the following aspects: the language knowledge has a dominant feature, to correctly understand the language knowledge; to recognize the relationship between language knowledge and language skills, the ability to be first, knowledge is the second; emphasis on the process of language knowledge learning, put an end to the practice of simply teaching; the language knowledge teaching must follow the basic principles of systemic, cognitive and communicative and so on.

(3) Learning strategies. From the use purpose of the strategy, the use of psychological and cognitive process, learning strategies are divided into four kinds of cognitive strategies, control strategies, communication strategies, and resource strategies. Teachers have a plan and a step to develop the students' learning strategies in the teaching. Change teaching ideas, strengthen the awareness of the cultivation of learning strategies; improving the understanding, and reducing the negative impact on student learning strategies; combined language learning, develop learning strategies; some of the principles to be followed in the cultivation of learning strategies, including demand principle, the purpose principle, combination principle, evaluation principles, the difference principle and planning principles, and so on.

(4) Emotional attitude. Emotion in language teaching refers to the interests, attitudes, motivation, self-confidence, autonomy and volition; these are personality factors that affect the learning process and learning effect, also student in the process of English learning need to cultivate the personality and character, but also the need to continue to train in the learning process. Good emotional factors are both teaching conditions, but also teaching objectives; teachers themselves to have good feelings; pay attention to the positive emotion of students; develop good emotion needs good classroom atmosphere; effective use of cooperative learning, promote the formation of positive emotions. 
(5) Cultural awareness. Cultural awareness teaching objectives include cultural knowledge, cultural understanding, intercultural communication, intercultural awareness and intercultural communicative competence five aspects and so on. Teachers themselves should have the intercultural awareness and intercultural communicative competence, and clear understanding of the language and culture, understanding of intercultural awareness and intercultural communicative competence, really to train students' intercultural awareness and intercultural communicative competence. Master and apply basic theories of intercultural communication, in the foreign activities can reasonably have to analyze the problems and the matters that should be paid attention to in the process of intercultural communication.

\section{Strategy on Intercultural Communicative Competence Cultivation in English and American Literature Teaching}

The study based on English and American literature course group construction and intercultural communicative comprehensive language using competence, English and American literature intercultural communicative competence strategies presented in teaching is as follows [3-10]:

(1) Using teaching model of translation classroom. As a product of information technology in education, flipped classroom educational philosophy has brought profound changes in teaching mode, "changes the traditional model that the teaching as the center and teach knowledge as target, builds the new mode that learning-centered and aimed to cultivate capacity, from the simple classroom learning into multiple learning ways". Constructivism emphasizes subjectivity and initiative of student in the acquisition process, under flipped classroom teaching model, students watch instructional videos by way of complete knowledge learning in the lessons, internalization absorb knowledge in classroom activities, under the guidance of teacher, actively construction of knowledge and maximize the absorption of knowledge. Flipped classroom allows students to give full play to self-learning ability, enhance self-learning level, for English and American literature teaching offers a new path, the basic orientation of undergraduate teaching English and American literature should be enlightened thinking, to develop the potential of thinking quality education curriculum, to ensure that students on work their reading experience. Low-grade students have more contact with literature, and high school students can grasp comprehensive knowledge of English and American literature, systematic training emotional competence and cultural understanding in intercultural communication. Guide students to think independently in English and American literature reading process, improve the ability to appreciate literature, improve language thinking ability, and cultivate aesthetic capacity.

(2) To improve student interest by means of modern educational technology. Modern educational technology is system of modern education means and methods which the modern educational theory applied to education and teaching practice. Modern technology means in educational teaching application, that the modern educational media; use of modern educational media carry out education and teaching activity methods, namely Media teaching method; optimization of education, systematic approach to the teaching process, namely instructional design. The English and American literature contains a large amount of information, rich media resources, is particularly suitable for the use of modern educational technology. Use computers, projectors and other modern equipment in teaching, vividly teach the course content; organize students to watch some foreign documentaries, through the famous directing movies or theater productions to enjoy, learn English and American literary works hidden in a foreign culture, feelings English and American culture, and organize the students to discuss research. Can also organize students on the basis of the original, give full play to the imagination of students, self-directed speech, the students understand the original manifested through direct involvement with literature, so that students in the ideology and the English and American cultural standards. By these means, not only to enable students to understand the true content of literary works, cultural connotation and political, economic and social context is more important to understand literary works.

(3) To change the teaching idea of the cultivation of intercultural communicative competence. Teaching idea is a concentrated expression of the understanding, but also people's views on 
teaching and basic attitudes and beliefs held by people engaged in teaching activities. Teaching idea articulated by teaching activities has an important guiding significance. In the process of English and American literature teaching, it is to cultivate intercultural communicative competence from the aspects of systematic, practical and communicative. Pay attention to the systematic, and systematically teach the time background and thinking mode of literature, to avoid complex and confusion of knowledge. On the basis of students' self reading, the teachers grasp and analyze the contents of the whole. Through exchanges and discussions, let the students experience the central idea of the work, and cultivate the students' understanding and analysis ability; highlight the practicality, select the literature works that are beneficial to the students' intercultural awareness, highlight the vivid of literature works, authenticity and a life consistency, allowing students to appreciate the works from life, stimulate interest in learning, improve learning motivation; reflect communicative, literature works are both cultural carrier and means of communication. Through the study of Western literature, so that students understand the vocabulary and language use methods to make cultural exchange between smoothly. Meanwhile, the culture and get a reasonable exchange and development through osmosis.

(4) Strengthen the cultivation of cultural empathy. Cultural empathy is the main cultural communication in intercultural communication, is a kind of psychological experience, emotional displacement and cognitive transformation, which is to ensure the smooth communication between different cultures, that is, consciously go beyond the psychological shackles of the national native language and culture, and the psychological tendency of thinking stand in another culture mode. Cultural empathy ability is an important part in the process of intercultural communicative competence cultivation, in strengthening students' intercultural communicative ability is indispensable. Because different countries and different regions have different cultures and peoples, and therefore needs to build the perfect way to communicate between different cultures, to establish a platform and the media for mutual understanding, with different ways of thinking to think about the problem of national culture, help in a variety of literature works to understand and master. In intercultural communicative competence training process, between different cultures find a meeting point, in the context of globalization, the integration of a variety of cultures, from the perspective of a variety of cultural analysis, in order to truly adapt to the development of the times. Cultural empathy is a subjective consciousness, only students from the perspective of their own consciousness, cultural consciously learn and master, it can be released from the shackles of local culture psychological and emotional level, so as to achieve the goal of harmony with people in different cultural backgrounds.

(5) Adopt teaching methods that are in conformity with the teaching content. Teaching methods include teachers to teach and students to learn, it is a unified method of teaching and learning methods. English and American literature teaching activities require a variety of learning mechanisms and multiple external environment and tools to achieve the organic combination of internal and external factors, the development of intercultural communicative competence in all aspects from cognitive, emotional and behavioral. Teaching methods may be employed include comparative methods and experience to explore methods and reading methods. Among them, the comparison method, the Chinese literature and English and American literature conducted with horizontal comparison, different periods of English and American literature longitudinal comparison, to help students understand the context of the development of English and American literature, for students' understanding of the history of English and American literature and the contents have a great help; experience exploring approaches to student-centered learning, create real or simulated intercultural communicative scenarios for students to feel and experience, so that cognitive, emotional and behavioral affected all aspects, and make up the shortage of teaching method. Reading methods, teacher predetermined appropriate reading materials for student, requirements within the prescribed time to read, and then organize students to discuss, ask students to turn in book review. Students in the reading process, not only to improve language comprehension ability, but also can improve thinking ability. 


\section{Conclusion}

English and American literature can subtly improve students' English language learning basic skills, and stimulate student interest in learning English, and helps them to understand Western culture, and improving the intercultural communicative competence of college students as a whole. With the development of world multi-polarization and economic globalization, the connection between the international is getting closer and closer, national and trade exchanges between the increasingly close. As a new era of college students, we must attach importance to the English and American literature, more contact with the English and American literature, to learn more about English and American literature, discovered the unique charm of English and American literature. The English and American literature have the value of philosophy, humanities and aesthetics, which can effectively improve the personality of college students and improve their own quality and cultural level, but also can cultivate intercultural communicative competence. Only by accepting English and American literature, understand western culture thought and value system, to truly understand the cultural differences between East and West, in order to adapt to social work and life in the future, can in the tide of economic globalization fly.

\section{References}

[1] D. B. Chen, Y. J. Yang, "Constructing Curriculum Group of Computer Control for Electron and Information Specialty," Journal of Huaibei Coal Industry Teachers College (Natural Science Edition), vol. 30, no. 1, pp. 79-82, 2009.

[2] Baidu library, "The cultivation of students' comprehensive language ability," http://wenku.baidu.com/link?url=slwYCUg9mtU0p2WvQsUUJ1hrS9OTYGEBPZx4Nh92GbJ NC59fb_FlexQSEPM-UEckHPza1pKudoW16siWtLfLXihBOiOnPBn9ESiPV1Fm5YS, 2015-12-1.

[3] Y. Q. Liu, "Talking about British and American literature teaching and cultivation of cross cultural awareness," Journal of Social Science of Jiamusi University, vol. 29, no. 3, pp. 156-157, 2011.

[4] Y. Tang, "On the cultivation of the cultural awareness of English and American literature courses," Heilongjiang Researches on Higher Education, vol. 29, no. 12, pp. 164-165, 2010.

[5] C. X. Liu, "The heterogeneity of English and American literature and cultivation of college students' intercultural awareness," Heilongjiang Researches on Higher Education, vol. 33, no. 2, pp. 140-142, 2014.

[6] Y. Y. Tao, "Discussion on the Cultivation of Cross Cultural Awareness in the Teaching of English Literature," Journal of Qiqihar Junior Teachers' College, vol. 35, no. 3, pp. 167-168, 2015.

[7] L. Fu, "On the Construction of Flipped Classroom Mode in College English," Journal of Inner Mongolia University of Finance and Economics, vol. 12, no. 6, pp. 113-114, 2014.

[8] S. H. Yang, "Flipped classroom and British and American literature teaching," Overseas English, vol. 16, no. 13, pp. 88-89, 2015.

[9] Y. Y. Wang, "On the heterogeneity of Anglo American literature and the cultivation of College Students' intercultural awareness," Culture Journal, vol. 10, no. 3, pp. 128-129, 2015.

[10] M. Xu, "An analysis of cross cultural awareness cultivation strategy in English literature teaching," Science \& Technology Vision, vol. 4, no. 6, pp. 182-183, 2014. 